\title{
Modification of Antinociceptive Action of Morphine by Dopamine Agonist and Antagonist in Mice
}

\author{
Katsuo KAMATA, Kunihiko OGAWA and Tsutomu KAMEYAMA \\ Department of Chemical Pharmacology. Faculty of Pharmaceutical Sciences. \\ Meijo University. Nagoya 468, Japan \\ Accepted February 28, 1985
}

\begin{abstract}
A marked potentiation of the antinociceptive action of morphine was produced by haloperidol, but apomorphine had no effect on the antinociceptive action of morphine in acute experiments. Following chronic treatment with haloperidol, the antinociceptive action of morphine was significantly suppressed by apomorphine, and apomorphine shifted the dose-response curve of morphine to the right and increased the ED50 value of morphine by 2.3 -fold. These results suggest that the suppressive action of apomorphine on the antinociceptive effect of morphine in chronic haloperidol-treated mice may be due to an increased sensitivity of postsynaptic dopaminergic receptors to apomorphine.
\end{abstract}

It has been reported that the nigrostriatal dopamine (DA) system responds to a variety of noxious stimuli, e.g., tail pinch, sciatic nerve stimulation or radiant heat $(1-3)$. Nieoullon et al. (4) reported that sensory stimulation influenced the release of DA in both the caudate nucleus and the substantia nigra. The caudate nucleus of the rat is particularly rich in opiate receptors $(5-7)$. Jurna and Heinz (8) reported that microinjection of morphine into the caudate nucleus produced a marked antinociceptive action. and this effect was abolished by i.p. injection of naloxone or apomorphine. These views led us to assume that the dopaminergic system is possibly involved in the regulation of the antinociceptive action of morphine. If this is the case, then the antinociceptive action of morphine should be influenced by apomorphine in animals treated chronically with haloperidol because of an increase in the sensitivity of postsynaptic dopaminergic receptors to apomorphine. The present study tested this hypothesis in an attempt to elucidate the role of the dopaminergic system in the antinociceptive action of morphine.

Male ddY-strain mice weighing between 18-22 g were used in all experiments. The animals were maintained in a constant environment with a $12 \mathrm{hr}$ dark and $12 \mathrm{hr}$ light cycle. The animals had free access to food and tap water ad libitum. At least one week was allowed for acclimatization to the environment before experimentation. Antinociceptive activity was evaluated by the tail-flick method. The reaction time of the tail-flick response evoked by heat focussed to the tip of the tail was determined with a stop watch in groups of 12 mice. The usual control tail-flick latency was $2-3 \mathrm{sec}$. The peak effect of morphine in this assay occurred $30 \mathrm{~min}$ after administration. The doses of morphine used in the present study were $1.25,2.5,5.0,10$ and $20 \mathrm{mg} / \mathrm{kg}$, i.p. The ED50 values and their $95 \%$ confidence interval were determined by the method of Litchfield and Wilcoxon (9). The ED50 of morphine following treatments with dopaminergic modifiers was considered significantly different from the control ED50 of morphine if the experimental ED50 lay outside the $95 \%$ confidence interval of the control ED50 and the control ED50 lay outside the 95\% confidence interval of the experimental ED50. Apomorphine and haloperidol were given 5 min before administration of morphine. For the chronic study, animals were administered with either $0.3 \%$ carboxymethylcellulose (CMC) (vehicle) or haloperidol $(2 \mathrm{mg} / \mathrm{kg}$. i.p.) daily for 21 consecutive days. Three days 
following the last administration, these mice were administered with a test dose of morphine $(1.25-20 \mathrm{mg} / \mathrm{kg}$, s.c.). Following this, the control observation for the antinociceptive action of morphine was made in one group. and the effect of apomorphine $(5 \mathrm{mg} / \mathrm{kg}$. i.p.) on the antinociceptive action of morphine was investigated in another group. Morphine sulfate and apomorphine $\mathrm{HCl}$ were dissolved in saline (in the case of apomorphine, a few grains of ascorbic acid were added to the solution to prevent oxidation). Haloperidol was dissolved in $0.3 \%$ CMC. Where applicable, all drug doses were expressed as the respective salts.

In acute experiments, haloperidol $(2 \mathrm{mg} /$ $\mathrm{kg}$, i.p.) exerted a significant enhancing action on the antinociceptive effect of morphine on the tail-flick response as shown in Fig. $1 \mathrm{~A}$ and decreased the ED50 of morphine by about 4-fold. Apomorphine ( 5 $\mathrm{mg} / \mathrm{kg}$, i.p.) had no influence on the antinociceptive action of morphine. Neither haloperidol $(2 \mathrm{mg} / \mathrm{kg}$ ) nor apomorphine (5 $\mathrm{mg} / \mathrm{kg}$ ) alone produced significant changes in the tail-flick response. Following chronic treatment with haloperidol, on the other hand, the antinociceptive action of morphine was significantly suppressed by apomorphine, and apomorphine (5 $\mathrm{mg} / \mathrm{kg}$, i.p.) shifted the dose-response curve of morphine to the right and increased the ED50 of morphine by 2.3-fold (Fig. 1B).

In the present study, haloperidol produced a significant enhancement of the antinociceptive action of morphine in the acute experiments. Apomorphine did not show any influence on the antinociceptive action of morphine even at a high dose $(5 \mathrm{mg} / \mathrm{kg}$ ). Thus, it can be anticipated that physiological stimulation of DA receptors attains the maximal inhibitory effect on the antinociceptive action of morphine in mice in the normal situation, and that further stimulation of the DA receptors by apomorphine does not modify the antinociceptive action of morphine. This inhibition can be removed when the DA receptors is blocked by haloperidol, thereby resulting in a potentiation of the antinociceptive action of morphine.

In the chronic study, it was found that DA receptors stimulation by apomorphine
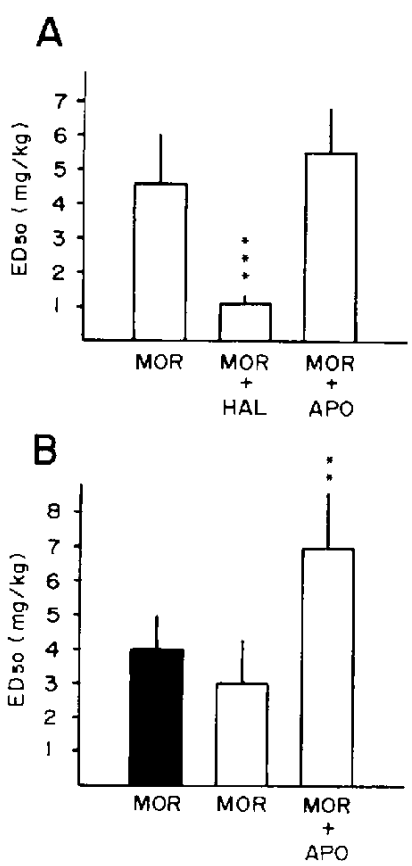

Fig. 1. Antinociceptive effect of morphine on the tail-flick response in mice. The columns represent the value of the ED50 of morphine. A. acute experiments; $B$, chronic experiments. Haloperidol and apomorphine were given $5 \mathrm{~min}$ before administration of morphine. In the chronic experiments, three days after cessation of chronic vehicle (W) or haloperidol (-) treatment, the control response for morphine's antinociceptive action was checked. ** MOR vs. MOR+APO $(P<0.01)$ in chronic haloperidoltreated mice and *** MOR vs. HAL (P<0.001) in acute experiments. MOR, morphine; HAL, haloperidol: APO. apomorphine.

decreased the antinociceptive effect of morphine when mice were in a state of dopaminergic supersensitivity following chronic treatment with haloperidol. The dose and length of haloperidol treatment employed in the present experiment were well established to produce a dopaminergic supersensitivity $(10,11)$. If the activity of dopaminergic neurons was completely suppressed due to a gradual development of a depolarization block of DA cells following chronic treatment with haloperidol (12-15), the antinociceptive action of morphine should be enhanced by the treatment. In animals treated chronically with haloperidol, however, morphine exerted 
an antinocicaptive action similar to that in the chronic vehicle-treated mice. It is conceivable. therefore, that some physiological activity of dopaminergic neurons after long-term treatment with haloperidol is still contributing to the inhibition of the antinociceptive action of morphine because of an increased sensitivity of the DA receptors. Further stimulation of dopamine receptors by apomorphine produced additional inhibition of the antinociceptive action of morphine, presumably due to the supersensitivity state of the dopaminergic system.

In conclusion, on the basis of the results from the present experiments, the suppressive action of apomorphine on the antinociceptive action of morphne in chronic haloperidoltreated mice, which could not be detected in acute experiments, may be due to an increased sensitivity of the postsynaptic dopamine receptors to apomorphine. This provides additional evidence to support the concept that the dopaminergic system is playing a role as an inhibitory modulator of the antinociceptive action of morphine in mice.

Acknowledgement: This research was supported, in part by Grant No. 56771107 from the Ministry of Education, Science and Culture, Japan.

\section{References}

1 Chiodo, L.A., Antelman, S.M., Caggiula, A.R. and Lineberry, C.G.: Sensory stimuli alter the discharge rate of dopamine (DA) neurons: Evidence for two functional types of DA cells in the substantia nigra. Brain Res. 189, 544-549 (1980)

2 Hommer, D.W. and Bunney, B.S.: Effect of sensory stimuli on the activity of dopaminergic neurons: Involvement of non-dopaminergic nigra neurons and striato-nigra pathways. Life Sci. 27 , 377-386 (1980)

3 Pay, S. and Barasi, S.: A study of the connections of nociceptive substantia nigra neurones. Pain 12, 75-89 (1982)

4 Nieoullon, A., Cheramy, A. and Glowinski, J.:
Nigra and striatal dopamine release under sensory stimuli. Nature 269, 340-342 (1977)

5 Pert, C.B. and Snyder, S.H.: Opiate receptor: Demonstration in nervous tissue. Science 179. 1011-1014 (1973)

6 Lee. C.-Y., Akera, T., Stolman, S. and Brody, T.M.: Saturable binding of dihydromorphine and naloxone to rat brain tissue in vitro. J. Pharmacol. Exp. Ther. 194, 583-592 (1975)

7 Atweh, S. and Kuhar, M.J.: Autoradiographic localization of opiate receptors in rat brain. III. The telencephalon. Brain Res. 134, 393-405 (1977)

8 Jurna, I. and Heinz, G.: Anti-nociceptive effect of morphine, opioid analgesics and haloperidol injected into the caudate nucleus of the rat. Naunyn Schmiedebergs Arch. Pharmacol. 309, 145-151 (1979)

9 Litchfield, J.T. and Wilcoxon, F.: A simplified method of evaluating dose-effect experiments. $J$ Pharmacol. Exp. Ther. 96, 99-113 (1949)

10 Muller, P. and Seeman, P.: Dopaminergic supersensitivity after neuroleptics: time-course and specificity. Psychopharmacology (Berlin) 60, 111 (1978)

11 Schwartz, J.C., Costentin, J., Martres, M.P., Protais, P. and Baudry, M.: Modulation or receptor mechanism in the CNS: Hypersensitivity to catecholoamine. Neuropharmacology 17,665685 (1978)

12 Bunney, B.S. and Grace, A.A.: Acute and chronic haloperidol treatment: Comparison of effects on nigral dopaminergic cell activity. Life Sci. 23 , 1715-1728 (1978)

13 Chiodo, L.A. and Bunney, B.S.: Typical and atypical neuroleptics: Differential effects of chronic administration on the activity of $A_{9}$ and $A_{10}$ midbrain dopaminergic neurons. J. Neurosci. 3, 1607-1619 (1983)

14 White, F.J. and Wang, R.Y.: Comparison of the effects of chronic haloperidol treatment on $A_{9}$ and $A_{10}$ dopamine neurons in the rat. Life Sci, 32, 983-993 (1983)

15 White, F.J. and Wang, R.Y.: Differential effects of classical and atypical antipsychotic drugs on $A_{9}$ and $A_{10}$ dopamine neurons. Science 221 , $1054-1057$ (1983) 